\title{
Corrigendum: Analyses of allele-specific gene expression in highly divergent mouse crosses identifies pervasive allelic imbalance
}

\author{
James J Crowley, Vasyl Zhabotynsky, Wei Sun, Shunping Huang, Isa Kemal Pakatci, Yunjung Kim, Jeremy R Wang, Andrew P Morgan, \\ John D Calaway, David L Aylor, Zaining Yun, Timothy A Bell, Ryan J Buus, Mark E Calaway, John P Didion, Terry J Gooch, \\ Stephanie D Hansen Nashiya N Robinson, Ginger D Shaw, Jason S Spence, Corey R Quackenbush, Cordelia J Barrick, \\ Randal J Nonneman, Kyungsu Kim, James Xenakis, Yuying Xie, William Valdar, Alan B Lenarcic, Wei Wang, Catherine E Welsh, \\ Chen-Ping Fu, Zhaojun Zhang, James Holt, Zhishan Guo, David W Threadgill, Lisa M Tarantino, Darla R Miller, Fei Zou, \\ Leonard McMillan, Patrick F Sullivan \& Fernando Pardo-Manuel de Villena \\ Nat. Genet. 47, 353-360 (2015); published online 2 March 2015; corrected after print 16 April 2015
}

In the version of this article initially published, an accession number was not provided for RNA-seq data sets. The RNA-seq data sets that passed quality control are available at the Sequence Read Archive (SRA) under accession SRP056236. The error has been corrected in the HTML and PDF versions of the article. 